\title{
A review of energy harvesting technology and its potential applications
}

\author{
Indrajit Sil*, Sagar Mukherjee, Kalyan Biswas \\ ECE Department, MCKV Institute of Engineering, Howrah 711204, India \\ Email: sil.indrajit25@gmail.com
}

\begin{abstract}
In the recent years, obtaining a sustainable form of energy to power various autonomous wireless $\&$ portable devices is increasingly becoming a matter of concern \& various alternate sources of energy have been explored. The concept of power harvesting works towards developing self-powered devices that do not require replaceable power supplies. This paper discusses energy harvesting or energy scavenging as an efficient approach to cater to the energy needs of portable electronics, review recent advancement in the field of power harvesting \& present the current state of power harvesting in its drive to create completely selfpowered devices.
\end{abstract}

Keywords: Energy Harvesting, Piezoelectric, Thermal, Thermoelectric, Vibration.

\section{INTRODUCTION}

The field of power harvesting has experienced significant growth over the past few years due to the ever-increasing desire to produce portable \& wireless electronics with extended lifespan $[1,2,3]$. Current portable \& wireless devices must be designed to include electrochemical batteries as the power source. The use of batteries can be troublesome due to their limited lifespan, thus necessitating their periodic replacement. In the case of wireless sensors that are to be placed in remote locations, the sensor must be easily accessible or of a disposable nature to allow the device to function over extended periods of time. Energy scavenging devices are designed to capture the ambient energy surrounding the electronics \& convert it into usable electrical energy. A number of sources of harvestable ambient energy exist, including thermal energy, sound energy, radio frequency, light, mechanical energy \& wind energy [2].

\section{SOURCE OF ENERGY HARVESTING}

\subsection{Thermal energy}

Thermal energy can be obtained from heat present in the ambience or from heat generated during some process. Either thermoelectric or pyroelectric effects can be used to harvest energy. Thermoelectric effects like Peltier effect, Seeback effect \& Thomson effects [1] can generate power as long as a heat source is present. Extraction of energy from a thermal source requires a thermal gradient $\&$ conversion efficiency mainly depends on the temperature difference between the heat source $\&$ the environment (i.e. the cold \& the hot side). A greater temperature difference leads to a better output.

\subsection{Mechanical energy}

Mechanical sources provide a promising alternative to harvest energy where vibration source is the best. Vibrations in some situations can be very large, like in case of the vibrations of civil structures like tall buildings, railroads, ocean waves, \& even human motions \& can give a better output power. Sources for conversion of vibration energy into electrical energy include electrostatic, magnetic field, or strain on a piezoelectric material [2].

\subsection{Sound energy}

Sound energy is another form of unused energy which can be harvested. Sound energy is almost present continuously \& at a considerable level in the environment for e.g. on the railway track, runway, ship yard, or on the road (engine noise of vehicles \& horns), loud music played in clubs or parties, at construction sites \& other such sources etc. give sufficient sound pressure levels that can be used for EH [3].

\subsection{Wind energy}

Wind energy is another method of harvesting energy. This wind flow, or motion energy, when harvested using huge wind turbines, can be used to generate electricity on a large scale [4]. 


\subsection{Radio frequency}

Radio frequency (RF) is any of the electromagnetic wave frequencies that lie in the range extending from around $3 \mathrm{kHz}$ to $300 \mathrm{GHz}$, which include those frequencies used for communications or radar signals. RF usually refers to electrical rather than mechanical oscillations [5].

\subsection{Light}

Light is electromagnetic radiation within a certain portion of the electromagnetic spectrum. Visible light is usually defined as having wavelengths in the range of 400-700 nanometers $(\mathrm{nm})$, between the infrared (with longer wavelengths) \& the ultraviolet (with shorter wavelengths). This wavelength means a frequency range of roughly 430 750 terahertz $(\mathrm{THz})$. [6]. A comparison of different energy source $\&$ their applications is tabulated in Table 1 .

Table 1. Different energy sources with their harvested power

\begin{tabular}{|c|c|c|c|}
\hline $\begin{array}{l}\text { Energy } \\
\text { Source }\end{array}$ & Characteristic & $\begin{array}{c}\text { Harvested } \\
\text { Power }\end{array}$ & Applications \\
\hline \multirow[b]{2}{*}{ Thermal } & Human & $60 \mu \mathrm{W} / \mathrm{cm}^{2}$ & \multirow{2}{*}{$\begin{array}{c}\text { Remote } \\
\text { Wireless } \\
\text { Sensors\& } \\
\text { Actuators }\end{array}$} \\
\hline & Industrial & $\stackrel{\sim 1-}{\sim 10 \mu \mathrm{W} / \mathrm{cm}^{2}}$ & \\
\hline \multirow[b]{2}{*}{ Mechanical } & Human & $\sim 4 \mu \mathrm{W} / \mathrm{cm}^{3}$ & \multirow{2}{*}{$\begin{array}{c}\text { Handheld } \\
\text { Electronic } \\
\text { Devices or } \\
\text { Remote } \\
\text { Wireless } \\
\text { Actuators } \\
\end{array}$} \\
\hline & Machines & $\underset{3}{\sim 800 \mu \mathrm{W} / \mathrm{cm}}$ & \\
\hline Sound & Machines & $\sim 10 \mu \mathrm{W} / \mathrm{cm}^{3}$ & $\begin{array}{c}\text { Small } \\
\text { Handheld } \\
\text { Electronic } \\
\text { Devices }\end{array}$ \\
\hline Wind & Environment & $\underset{3}{\sim 100 \mu \mathrm{W} / \mathrm{cm}}$ & $\begin{array}{c}\text { Remote } \\
\text { Wireless } \\
\text { Sensors } \\
\end{array}$ \\
\hline \multirow[b]{2}{*}{ Light } & Outdoor & $100 \mathrm{~mW} / \mathrm{cm}^{2}$ & \multirow{2}{*}{$\begin{array}{c}\text { Handheld } \\
\text { Electronic } \\
\text { Devices }\end{array}$} \\
\hline & Indoor & $100 \mu \mathrm{W} / \mathrm{cm}^{2}$ & \\
\hline \multirow[b]{2}{*}{$\begin{array}{c}\text { Radio } \\
\text { Frequency }\end{array}$} & GSM 900 & $0.1 \mu \mathrm{W} / \mathrm{cm}^{2}$ & \multirow{2}{*}{$\begin{array}{l}\text { Remote } \\
\text { Wireless } \\
\text { Sensors }\end{array}$} \\
\hline & WiFi & $\begin{array}{l}0.001 \\
\mu \mathrm{W} / \mathrm{cm}^{2}\end{array}$ & \\
\hline
\end{tabular}

\section{APPLICATION OF ENERGY HARVESTING}

\subsection{Biomedical applications}

The extension of the energy harvesting concept is used for portable medical devices. The portable medical devices are expected to be smaller in size, lightweight\& most of the times either wearable (for e.g. the sphygmomanometer) or implanted inside the body (for e.g. the pacemaker). As these devices are smaller in size, their energy consumption is also less. Batteries of smaller size are enough to meet these requirements but the operational time $\&$ performance of the portable devices as these batteries need to be replaced or recharged periodically. A person with lithium battery pacemaker will require battery replacement surgery every 8 years. Photo of a Pacemaker with battery is shown in Figure
1 [7]. Likewise, implantable neurostimulator \& infusion pumps have a reduced lifespan of 3 to 5 years. Thus dependence on batteries need to be reduced in this field giving rise to energy harvesting as an alternative solution. Piezoelectricity, thermal energy \& electromagnetic energy w.r.t to human body are mainly considered for biomedical EH. Thermoelectric devices are an attractive source of energy as it directly converts temperature gradients in to power. Though thermoelectric generators (TEG) were available for quite some time, it is only recently that low power medical implants have been researched \& developed [7].

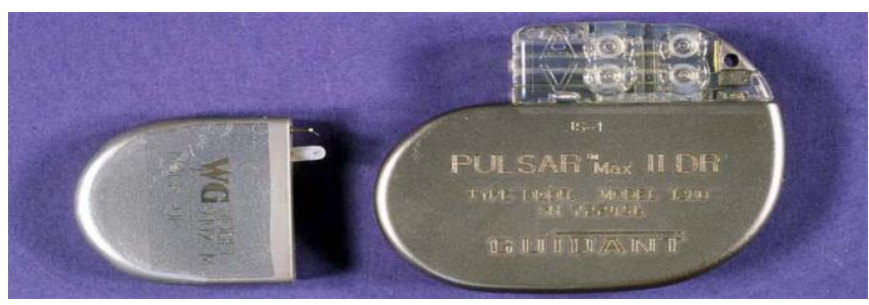

Figure 1. Pacemaker with battery

\subsection{Wireless networks}

Energy harvesting concept has found a variety of applications in wireless communication \& networks. Some adhoc sensor networks follow minimum energy path to optimize energy usage at a node such that the limited resources at sensor nodes can be used more effectively. Photo of a Wireless Sensor Network is shown in Figure 2 [8]. At the same time, if a low energy path is used frequently, it may lead to reduction in the node energy along that path \& may even cause network partition. Hence occasionally suboptimal paths based on energy aware routing protocols may be used to improve the performance with the help of EH. Use of energy harvesting helps to eliminate the need of battery replacement \& maintenance \& to prolong the lifetime of sensor nodes [8].

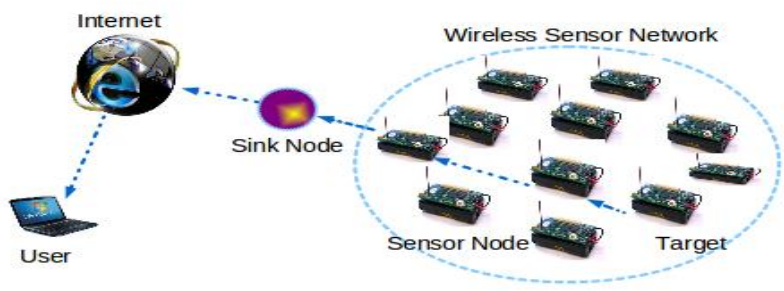

Figure 2. Wireless sensor network

\subsection{Other applications}

Energy harvesting has also found its scope in some industrial applications, for e.g. a TEG developed through an AC Condenser using measurements from several thermometers placed inside its condenser unit is a recent application based on thermal energy [1]. Piezoelectric shoe [9, 10] is another application where a piezoelectric material (PFCB) is inserted inside the sole of the shoe. A sensor senses the walking, running or other vibrations occurring on the PFCB \& converts it to energy which can be used to power small electronics. Another example is energy harvesting in a club environment by placing an energy conversion mechanism on the dance floor which will convert 
the vibrations due to dancing motion into electrical energy. Solar windows [11], smart wall papers [12] \& light weight solar cells [13] are some applications based to solar energy conversion.

\section{CURRENT STATUS OF ENERGY HARVESTING TECHNIQUES}

\subsection{Mechanical (vibration) energy harvesting}

A study has been done on energy harvester mounted on sneakers that generated electrical energy from pressure on the shoe sole by Kymissis et al. [14]. The first energy harvesters had multilayer laminates of PVDF, the second one contained a PZT unimorph \& the third one was a rotary electromagnetic generator. The PVDF \& PZT element mounted between the removable insole \& rubble sole. The PVDF stack was in the front of the shoe while the PZT unimorph was at the heel.

A mini-scale piezoelectric energy harvester was developed by Roundy et al. [15, 16] which have a similar structure to what have been demonstrated by S. Beeby [18]. The harvester is used piezoelectric instead of silicon wafer as the cantilever beam, \& tungsten alloy as the proof mass instead of the magnets.

Sodano, Inman, \& Park [17] suggested method alters mechanical energy into electrical energy by straining a piezoelectric material. Strain or deformation of a piezoelectric material causes charge separation across the device, producing an electric field \& consequently a voltage drop proportional to the stress applied.

A mini-scale electromagnetic energy harvester prototype that consists of a coil \& a silicon wafer cantilever beam shown in Figure 3, with four pole magnets as its proof mass was developed by Beeby et al. [18, 19]. The harvester was able to produce considerably high power over its size. The mechanical \& electrical equivalent of the energy harvester design is shown in Figures $4 \& 5$ respectively.

Barker et al. [20] described that the high temperature energy harvester, incorporating silicon carbide electronics \& a PZT energy harvester can operate at 300 Celsius. The system comprises of a PZT piezoelectric energy harvester with silicon carbide Schottky diode full wave rectifier, which can rectify the AC supplier by the piezoelectric harvester at higher temperatures than conventional silicon components. In the case of vibration energy harvesting, this can be dramatically increased output voltage from the device. At resonance, the peak tip displacement of the bi-morph will be much greater \& so will significantly increase the stress in the piezoelectric layers. As the temperature increases, the voltage drop of the SiCschottky diode decreases, same as 300 Celsius voltage drop of a single diode of $0.1 \mathrm{~V}$.

The vibrations energy harvesting principle using piezoelectric materials into designing piezoelectric generator \& installed it on a bicycle handlebar to supply portable electrical energy was done by Minazara et al. [21]. The advanced piezoelectric generator that harvests mechanical vibrations energy is available on a bicycle. Based on the observations, this experiments that have conducted have shown that the few $\mathrm{mW}$ that produced by the piezoelectric generator is able to power bike LED lamp. A static converter transforms the electrical energy in a suitable form to the targeted portable application. Bike vibrations are converted into electricity via piezoelectric element. Embarked piezoelectric transducer, which is an electromechanical converter, undergoes mechanical vibrations therefore produce electricity. The electricity produced is thereafter formatted by a static converter before supplying a storage system or the load.

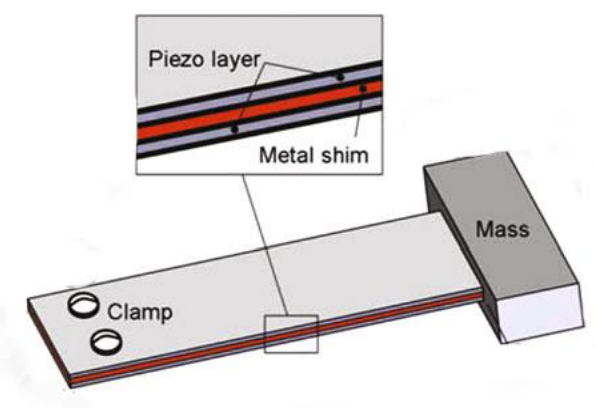

Figure 3. PZT coated cantilever beam

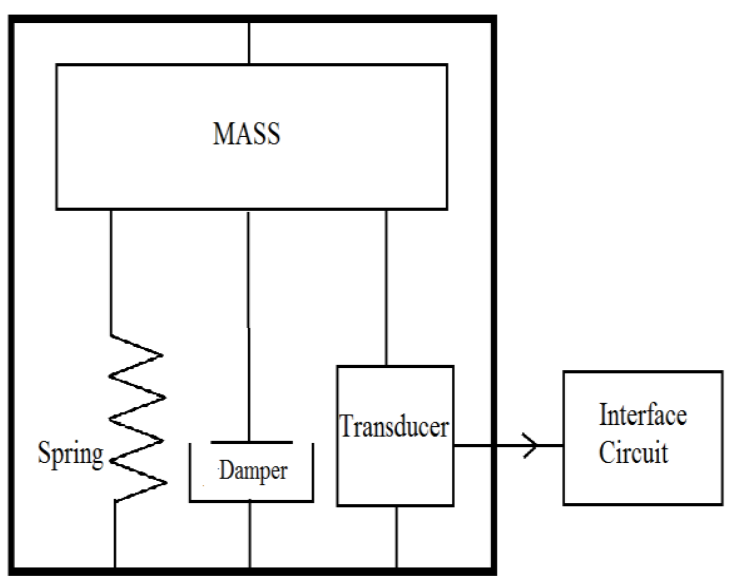

Figure 4. Mechanical equivalent model of PEH

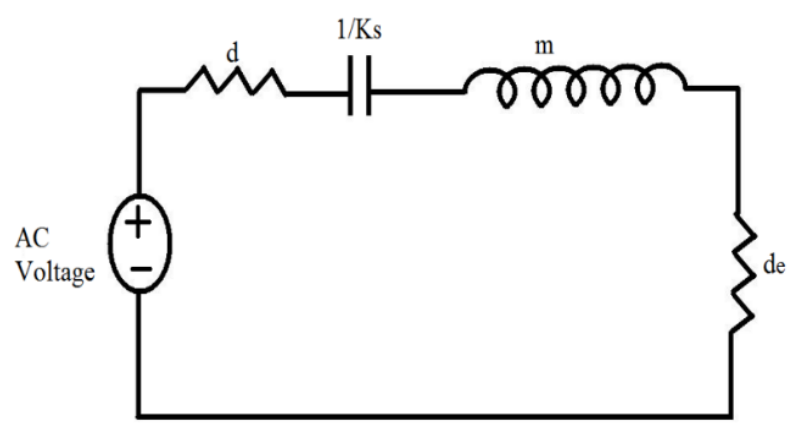

Figure 5. Electrical equivalent model of a PEH

$\mathrm{K}_{\mathrm{s}}=$ Stiffness of the Spring, $\mathrm{m}=$ Mass, $\mathrm{z}(\mathrm{t})=$ Mass Position, $\mathrm{d}=$ Damping

MO, Wright et al. [22, 23] demonstrated the pressure fluctuating systems, where circular diaphragm based energy harvesters have been employed to power up systems. It basically updates changes of voltage generated on the surface of the piezoelectric layer with respect to fluctuation of applied pressure \& also implemented in piezoelectric actuation.

Kotmann \& Hoffman et al. [24] describes an approach to harvesting electrical energy from a mechanically excited piezoelectric element. By employing the capacitive impedance, mechanical vibration of varying amplitude can be 
harvested into energy. For optimal power flow purpose, an energy harvesting circuit is proposed which consists of an ac-dc rectifier with an output capacitor, an electrochemical battery, \& a switch-mode dc-dc converter that controls the energy flow into the battery.

William et al. [2] developed the generic model, where energy can be harvested from piezoelectric materials by comparing the second order control systems which basically provides the mechanical energy, also defined as the kinetic energy. The electrical equivalent circuit provides relative amount of electrical energy, where charge density \& voltage generation according to load on the surface of the piezoelectric layer can be realized [25].

A PZT model for harvesting energy from structural sensors on a bridge or global positioning service (GPS) tracking devices was developed by Sodano, Inman et al. [26]. They established an experimental method to calculate charge accumulated on the surface of the PZT layer under applied strain. This model in turn simplifies design procedure necessary for determining the appropriate size \& vibration levels which is necessary for accurate sufficient energy to be produced \& supplied to the electronic devices.

Carrol \& Duffy [27] reported a sliding electromagnetic generator placed inside the shoes sole or energy harvesting. This device extracted electrical energy from the kicking force during walking. The generator consists of a set of three coils with magnets moving inside the coils.

\subsection{Thermal energy harvesting}

$\mathrm{Wu}$ et al. [28] proposed the concept of a waste-heat thermoelectric generator, the specific power output of the generator was analyzed \& compared with that of Carnot. They concluded that a completely reversible heat engine played a major role in the development of the performance of thermoelectric generators.

Rowe et al. [29, 30] investigated the ability to construct a large thermoelectric generator capable of supplying 100 watts of power from hot waste water. The system tested used numerous thermoelectric devices placed between two chambers, one with flowing hot water \& the other with cold water flowing in the opposite direction, thus maximizing the heat exchange. With a total of 36 modules, each with 31 thermocouples, 95 watts of power could be generated.

A low power thermoelectric generator (microthermoelectric harvester) capable of generating tens of microwatts of power $\left(15 \mu \mathrm{W} / \mathrm{cm}^{2}\right.$ from a $10^{\circ} \mathrm{C}$ temperature differential) out of a device that had previously generated nanowatts with the same size was developed by Stordeur et al. [31]. The device was based on thin film thermoelectric materials, consisted of 2250 thermocouples, \& operated in temperatures ranging from room to not higher than $120^{\circ} \mathrm{C}$.

Fleming et al. [32] investigated the use of thermoelectric generator (TEG) for powering microscale air vehicles. The idea is to integrate the TEGs as part of the airframe power plant assembly to reclaim a portion of the engine's waste heat as electric power. A TEG was mounted on the exhaust system of an internal combustion engine that was shown to generate $380 \mathrm{~mW}$ of power.

A prototype thermoelectric generator mounted oneselfignition (Diesel) engine was designed \& tested by Wojciechowski et al. [33] The designed model was able to recover even $25 \mathrm{~kW}$ of heat energy. Assuming the $5 \%$ efficiency of the thermoelectric modules it could allow to obtain the maximum electric power of app. 750W. A TEG unit was around the exhaust pipe. The unit was experimentally tested by Birkholz et al. [34] \& found to generate an open circuit voltage of $22 \mathrm{~V} \&$ a total power of 58W.

An exhaust system using ten TEG modules \& a liquid heat exchanger to maximize the thermal gradient was constructed by Matsubara [35]. The system was tested on a 2000cc class automobile $\&$ shown to produce $266 \mathrm{~W}$ of power. Wang et al. [36] have been successfully prepared one-dimensional n-type \& p-type Bi2Te3 nanowire arrays by electrochemical deposition (ECD) technology. Gonzalo [37] tackled the field of pyroelectric power generation in the mid 1970's, he concluded that with proper material selection, a pyroelectric power generator that used only one pyroelectric material could achieve a maximum efficiency of $4 \%$, which corresponds to $17 \%$ of the Carnot efficiency.

A large advancement was obtained in the field of pyroelectric conversion by Olsen's Group [38, 39]. They proposed the first pyroelectric conversion cycle named 'Olsen cycle' or 'Ericsson cycle' (electric analogous of the Ericsson heat engine cycle). They measured this thermodynamic cycle in terms of charge-voltage (polarization versus applied electric field) behavior on a new material -- copolymer P(VDF-TrFE). Between $23 \& 67^{\circ} \mathrm{C}$, each conversion cycle was able to generate $30 \mathrm{~mJ} / \mathrm{cm}^{3}$ of output electric energy density by applying maximum electric field $55 \mathrm{kV} / \mathrm{mm}$

Guyomar et al. [40] investigated the feasibility of heat energy harvesting on PVDF film combining with the synchronized switch harvesting on inductor (SSHI) technique. For amplitude variations of temperature from 0.5 to $8 \mathrm{~K}$, the conversion efficiency is found about $0.02 \%$ of Carnot thermodynamic cycle with a standard interface, \& the SSHI technique increases the converted energy by a factor which is about 2.5 times of the standard interface. The produced electrical power for temperature amplitude $7 \mathrm{~K}$ is more than $0.3 \mathrm{~mW}$ for an energy harvesting device composed for $8 \mathrm{~g}$ of active material.

A CMOS micro electromechanical systems-based thermoelectric power generators (TPGs) to convert waste heat into a few microwatts of electrical power in which Phosphorus \& boron heavily doped polysilicon thin films are patterned and electrically connected to consist thermopiles in the TPGs was designed, modelled, fabricated, \& characterized by Jin Xie et al. [41].The designed model for a device in the size of $1 \mathrm{~cm}^{2} \&$ with a $5-\mathrm{K}$ temperature difference across the two sides, the open-circuit voltage was found to be $16.7 \mathrm{~V} \&$ the output power of $1.3 \mu \mathrm{W}$ under matched load resistance.

A complete thermal energy harvesting power supply for implantable pacemakers in which designed power supply included an internal startup \& did not need any external reference voltage was designed by Mohammadreza Ashraf et al. [7]. The startup circuit included apre-startup charge pump (CP) \& a startup boost converter. The system was designed so that no failure occurs under overload conditions. According to their HSPICE simulation results, the circuit operated from input voltages as low as $40 \mathrm{mV}$ provided from a thermoelectric generator $\&$ generated output voltages up to $3 \mathrm{~V}$. A maximum power of $130 \mathrm{Mw}$ was obtained from the output of the boost converter. A typical TEG \& its system architecture which was used in the design is shown in Figure $6 \& 7$ respectively. 


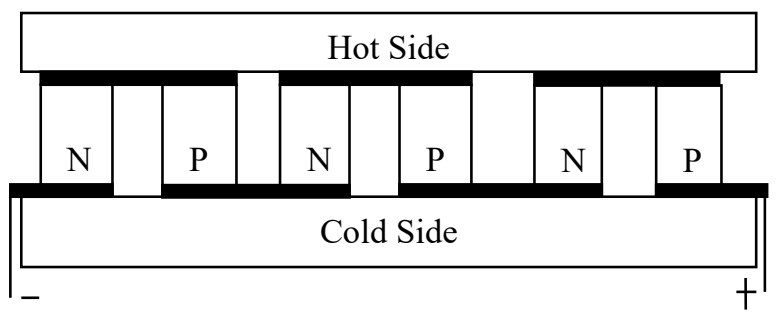

Figure 6. A typical TEG

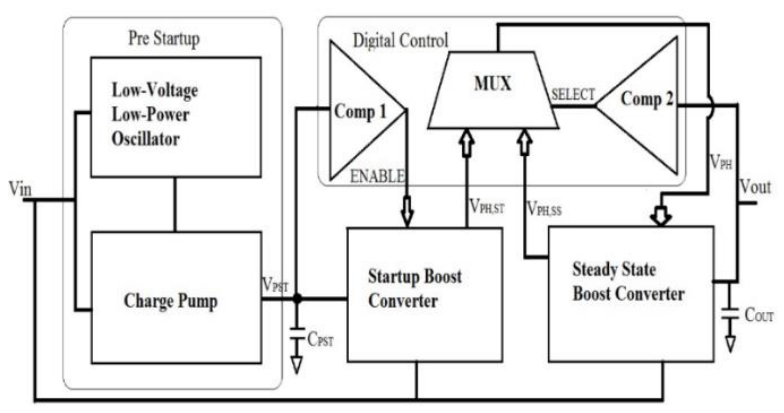

Figure 7. TE energy harvesting system architecture

\subsection{EH techniques of our interest}

Vibrations \& thermal or heat is always found in the environment, large or small can be used to power other small devices thereby reducing the need of use of non-renewable energy sources for its power requirement which can be easily met by using the proposed two EH techniques. Light though available in abundance in the ambient cannot produce much of the power \& also the devices used to harvest light energy is larger in size whereas small devices with alterable parts can be put together to harvest the two proposed EH techniques. Factories \& vehicles are found in abundance in the world \& harvesting the heat \&vibration energy generated from the machines in vehicles and factories into useful energy to power up small devices like mobile phone batteries, chargeable batteries etc. will greatly reduce the need of nonrenewable energy sources which are at a verge of exhaustion.

\section{CONCLUSIONS}

Energy harvesting has become an important aspect in the modern age because of rapid exhaustion of non-renewable sources for different applications. A review of different energy harvesting techniques is done in this work. Special focus has been given on vibration \& thermal energy harvesting because of their large harvested power is given in Table 1. Many research \& works has been done before \& there are still active researches are going on to investigate a number of alternatives to extract energy from the environment \& convert it to electrical energy to power an electronic device. With the advancement in technology and reduction in device sizes it is possible to increase the generated energy using new transducer designs or new materials, as well as innovative power conditioning circuits $\&$ energy storage elements. Also, the combination in the same device of several energy harvesting strategies will increase its capabilities to obtain energy in different situations.

\section{REFERENCES}

[1] Faruk Y., Coogler K.L. (2014). Low power energy harvesting with a thermoelectric generator through an air conditioning condenser, $121^{\text {st }}$ ASEE Annual Conference \& Exposition, Indianapolis, IN, Paper ID. Vol. 10552.

[2] William Y. (1996). Analysis of micro-electric generator for Microsystems, Sensors \& actuators A52, pp. 8-11. DOI: 10.1109/SENSOR.1995.717207

[3] Müller G., Möser M. (2012). Handbook of Engineering Acoustics, Springer, p. 7. ISBN 9783540694601.

[4] Fthenakis V., Kim H.C. (2009). Land use \& electricity generation: A life-cycle analysis, Renewable \& Sustainable Energy Reviews, Vol. 13, No. 6-7, p. 1465.

[5] Beasley J.S., Miller G.M. (2008). Modern Electronic Communication (9th ed.). pp. 4-5. ISBN 978-0132251136.

[6] Laufer G. (1996). Introduction to Optics \& Lasers in Engineering, Cambridge University Press, p. 11, ISBN 978-0-521-45233-5.

[7] Mohammadreza A., Nasser M. (2016). A thermal energy harvesting power supply with an internal startup circuit for pacemakers, IEEE Transactions on Very Large Scale Integration (VLSI) Systems, Vol. 24, No. 1. DOI: 10.1109/TVLSI.2015.2391442

[8] Dean T. (2010). Network + Guide to Networks (5th ed.), Cengage Learning, Boston, ISBN 978-1-4239-0245-4.

[9] Mitcheson P.D. (2008). Energy harvesting from human \& machine motion for wireless electronic devices, Proceedings of IEEE, pp. 1457-1486. DOI: 10.1109/JPROC.2008.927494

[10] Shenck, Nathan S., Joseph A. (2001). Energy scavenging with shoe-mounted piezo electrics, IEEE Micro, Vol. 3, pp. 30-42. DOI: 10.1109/40.928763

[11] Chow, Tin-tai, Li C.Y., Zhang L. Innovative solar windows for cooling-demand climate, Solar Energy Materials \& Solar Cells, pp. 212-220. DOI: 10.1016/j.solmat.2009.09.004

[12] Loughran J. University of Surrey. Light-absorbing graphene to power "smart wallpaper" and IoT from https://eandt.theiet.org/content/articles/2016/02/lightabsorbing-graphene-to-power-smart-wallpaper-andiot/, accessed on 29 February 2016.

[13] Chandler D.L., Massachusetts Institute of Technology, Solar cell as light as a soap bubble, from http://news.mit.edu/2016/ultrathin-flexible-solar-cells$\underline{0226}$, accessed on 25 February 2016.

[14] Kymissis J., Kendall C., Paradiso J., Gershenfeld N. (1998). Parasitic power harvesting in shoe, digest of papers, Second International Symposium on Wearable Computers, Pittsburgh, Pennsylvania, USA, pp. 132139. DOI: $10.1109 /$ ISWC.1998.729539

[15] Roundy S., Wright P.K. (2004). A piezoelectric vibration based generator for wireless electronics, Smart Materials \& Structures, Vol. 13, pp. 1131-1142. DOI: $10.1088 / 0964-1726 / 13 / 5 / 018$

[16] Roundy S., Wright P.K., Rabaey J. (2003). A study of low level vibrations as a power source for wireless sensor nodes, Computer Communications, Vol. 26, No. 11 pp. 1131-1144. DOI: 10.1016/S01403664(02)00248-7

[17] Sodano H.A., Park G., Inman D.J. (2004). Estimation of electric charge output for piezoelectric energy 
harvesting, Strain, Vol. 40, pp. 49-58. DOI: 10.1111/j.1475-1305.2004.00120.x

[18] Beeby S.P., Tudor M.J., White N.M. (2006). Energy harvesting vibration sources for microsystems applications, Measurement Science \& Technology, Vol. 17, pp. 175-195. DOI: 10.1088/0957-0233/17/12/R01

[19] Beeby S.P., Torah R.N., Tudor M.J. Glynne-Jones P.O., Donnell T., Saha C.R., Roy S. (2007). A micro electromagnetic generator for vibration energy harvesting" Journal of Micromechanics \& Micro engineering, Vol. 17, pp. 1257-1265. DOI: 10.1088/0960-1317/17/7/007

[20] Barker S., Vassilevski K.V., Wright N.G., Horsfall A.B. (2010). High temperature vibration energy harvester system, Conference, IEEE sensor, Kona, HI, pp. 300-303. DOI: 10.1109/ICSENS.2010.5689870

[21] Minazara, Vasic D., Costa F. (2014). Piezoelectric generator harvesting bike vibrations energy to supply portable devices, Australian Mining Technology Conference, pp. 1-6.

[22] Mo C., Radziemski L.J., Clark W.W. (2010). Analysis of piezoelectric circular diaphragm energy harvesters for use in a pressure fluctuating systems, Smart Materials \& Structures, Vol. 19, No. 2, article ID 025016.

[23] Mo C., Wright R., Slaughter W.S., Clark W.W. (2006). Behaviour of a unimorph circular piezoelectric actuator, Smart Materials \& structures, Vol. 15, No. 4, pp. 1094-1102.

[24] Kotmann G., Hofmann H.F., Lesieutre G.A. (2003). Optimized piezoelectric energy harvesting circuit using step down converter in discontinuous conduction mode, IEEE transactions on power Electronics, Vol. 18, No. 2, pp, 696-703. DOI: $\underline{\text { 10.1109/TPEL.2003.809379 }}$

[25] Kameierski T.J., Beeby S. (2011). Energy harvesting systems: principles, modelling \& applications, Springer science, Berlin, Heidelberg.

[26] Sodano H.A., Inman D.J. (2004). A review of power harvesting from vibration using piezoelectric materials, The Shock \& Vibration Digest, Vol. 36, pp. 197-205. DOI: $10.1177 / 0583102404043275$

[27] Carroll D., Duffy M. (2005). Demonstration of wearable power generator, Proceedings of the $11^{\text {th }}$ European Conference on Power Electronics \& Applications, Dresden, Germany, pp. 1-10. DOI: 10.1109/EPE.2005.219730

[28] Wu C. (1996). Analysis of waste-heat thermoelectric power generators, Applied Thermal Engineering, Vol. 16, pp. 63-69. DOI: $\underline{10.1016 / 1359-4311(95) 00014-5}$

[29] Rowe M.D., Min G., Williams S.G., Aoune A., Matsuura K., Kuznetsov V.L., Fu L.W. Thermoelectric recovery of waste heat - case studies. DOI: 10.1109/IECEC.1997.661919

[30] Rowe D.M., Kuznetsov V.L., Kuznetsova L.A., Min G. (2002). Electrical \& thermal transport properties of intermediate-valence $\mathrm{YbAl}_{3}$, Journal of Physics D: Applied Physics, pp. 2183-2186. DOI: 10.1088/00223727/35/17/315

[31] Stordeur M., Stark I. (1997). Low power thermoelectric generator-self-sufficient energy supply for micro systems, Proc. 16th Int. Conf. Thermo electrics, pp. 575-577. 10.1109/ICT.1997.667595

[32] Fleming J., Ng W., Ghamaty S. (2004). Thermo electric based power system for unmanned-airvehicle/microair-vehicle applications, Journal of Aircraft, Vol. 41, pp. 674-676.

[33] Wojciechowski K., Merkisz J., Fuć P., Lijewski P., Schmidt M., Zybała R. (2007). Study of recovery of waste heat from exhaust of automotive engine, 5th European Conference on Thermo electrics, Odessa, Ukraine, pp. 194-198. DOI: 10.1007/s11664-009$\underline{1010-1}$

[34] Birkholz U., Grob U.E., Riffel M., Roth H., Stohrer U. (1988). Conversion of waste exhaust heat in automobile using $\mathrm{FeSi}_{2}$ thermo elements, Proc. of the 7th International Conference on Thermoelectric Energy Conversion, Arlington, VA, pp. 124-128.

[35] Matsubara K. (2002). Development of a high efficient thermoelectric stack for a waste exhaust heat recovery of vehicles, Proc. of the 21st International Conference on Thermoelectronics, August 25-29th, Portland, OR, pp. 418-423. DOI: $10.1109 /$ ICT.2002.1190350

[36] Wang J., He J., Chen J., Zhou Y. (2002). Regenerative characteristics of electro caloric Stirling or Ericsson refrigeration cycles, Energy Conversion \& Management, Vol. 43, pp. 2319-2327.

[37] Gonzalo J.A. (1976). Ferroelectric materials as energy converters, Ferroelectrics, Vol. 11, pp. 423-429.

[38] Olsen R.B., Bruno D.A., Briscoe J.M., Jacobs E.W. (1985). Pyroelectric conversion cycle of vinylidene fluoride-trifluoro ethylene copolymer, Journal of Applied Physics, Vol. 57, pp. 5036-5042. DOI: $\underline{10.1063 / 1.335280}$

[39] Olsen R.B., Bruno D.A., Briscoe J.M., Dullea J. (1985). High electric field resistivity \& pyroelectric properties of vinylidene fluoride-trifluoro ethylene copolymer, Journal of Applied Physics, Vol. 58, p. 2854. DOI: $10.1063 / 1.335857$

[40] Guyomar D., Sebald G., Lefeuvre E., Khodayari A. (2009). Toward heat energy harvesting using pyroelectric material, Journal of Intelligent Material Systems \& Structures, Vol. 20, pp. 265-271. DOI: 10.1177/1045389X08093564

[41] Xie J., Lee C.K., Feng H.H. (2010). Design, fabrication, \& characterization of CMOS mems-based thermoelectric power generators, Journal of Microelectromechanical Systems, Vol. 19, No. 2. DOI: $\underline{10.1109 / J M E M S .2010 .204103 ~}$ 